\title{
PREVALÊNCIA DOS SINTOMAS DO TRATO URINÁRIO INFERIOR E IMPACTO NA QUALIDADE DE VIDA DE CRIANÇAS E ADOLESCENTES COM ANEMIA FALCIFORME
}

\author{
$\underline{\text { Alana de Medeiros Nelli }}{ }^{1}$; José de Bessa Junior ${ }^{2}$; Mateus de Andrade Alvaia ${ }^{3}$; Heros \\ Aureliano Antunes da Silva Maia ${ }^{4}$. \\ 1. Bolsista PROBIC/UEFS, Graduanda em Medicina, Universidade Estadual de Feira de Santana, email: \\ medeirosnelli@gmail.com \\ 2. Orientador, Departamento de Saúde, Universidade Estadual de Feira de Santana, email: josedebessa@gmail.com \\ 3. Participante do NUDES, Universidade Estadual de Feira de Santana, email: mateus_alvaia@ hotmail.com \\ 4. Participante do NUDES, Universidade Estadual de Feira de Santana, email: herosmaia@ hotmail.com
}

Palavras-chave: doença falciforme; sintomas do trato urinário inferior; qualidade de vida.

\section{INTRODUÇÃO}

A doença falciforme (DF) define-se como doença hereditária monogênica, autossômica recessiva crônica em que a hemoglobina $\mathrm{S}(\mathrm{HbS})$ está presente. Apresenta-se sob a forma de episódios agudos ou complicações clinicamente tratáveis, com maior gravidade na vigência de homozigose (SS) (Cançado, 2007; Portocarrero 2012; Field, 2008). Destaca-se mundialmente como a hemoglobinopatia congênita mais comum, afetando principalmente africanos ou seus descendentes na América (Anele, 2015; Claudino, 2012). No Brasil, exibe frequência variável de 2 a 6\%, cerca de 1:1000 nascidos-vivos, totalizando 20-30 mil brasileiros, assumindo a posição de doença genética mais prevalente. As maiores taxas de mortalidade estão entre os jovens, especialmente os menores de nove anos. (Ekinci, 2013; Eneh, 2015).

Os sintomas do trato urinário inferior (STUI) incluem uma série de queixas associadas tanto ao armazenamento quanto ao esvaziamento vesical (Portocarrero, 2012; Lorencini, 2015). Desordens que afetem qualquer uma destas funções vesicais básicas geram os STUI. A DF aumenta o volume urinário por prolongar o tempo de enchimento vesical e envolve dano celular por radicais livres oxidativos, gerando, entre outros, a enurese por hipostenúria e/ou instabilidade vesical (Portocarrero, 2012; MBong, 2013; Silva, 2014).

O DSM-IV aborda enurese como a perda de urina na cama ou roupas, involuntária ou não intencional, no mínimo 2 vezes na semana por no mínimo 3 meses consecutivos ou a presença de comprometimento social em uma criança de 5 anos ou mais e ocorrência desvinculada ao uso de uma substância ou efeito de condição médica prévia (Claudino, 2012). Sua prevalência cai com o avançar da idade, mas em pacientes falcêmicos, mantêm-se alta se comparada com a de pessoas sem a condição (Tewari, 2016).

A aquisição de desordens psiquiátricas como a depressão advém do fato de se tratar de doença crônica, requisitante de cuidados precoces, da imprevisibilidade das crises, modificações físicas, atraso na maturação sexual e restrições impostas pelo tratamento. Em crianças e adolescentes, tais transtornos manifestam-se sob a forma de desordens alimentares, desvios de comportamento e conduta, inabilidade no ajustamento social (Eneh, 2015; Wolf, 2014; MS, 2016).

Dessa maneira, este estudo transversal visa avaliar aspectos epidemiológicos dos STUI bem como o impacto dos mesmos na vida das pessoas a fim de proporcionar uma melhor abordagem do tratamento destas condições, permitindo a elaboração de políticas públicas mais realistas e minimização dos agravos associados à tão grave condição.

\section{MATERIAIS E MÉTODOS}

Trata-se de um estudo transversal observacional (cross-sectional), no qual foram avaliados pacientes na faixa etária dos cinco aos 24 anos, com doença falciforme, acompanhados em Centro de Referência localizado no município de Feira de Santana, interior 
da Bahia/Brasil. A pesquisa foi desenvolvida entre os meses de Setembro de 2016 e Julho de 2017. Foram considerados elegíveis à participação todos os sujeitos inclusos nesta faixa etária, atendidos no Centro de Referência no período designado. Após assinatura do Termo de Consentimento Livre e Esclarecido (TCLE), em conformidade com a Resolução nº 466/2012, os participantes, acompanhados ou não de seus responsáveis, responderam a um questionário estruturado acerca das características sociodemográficas e dos STUI (enurese noturna, noctúria, urgência, incontinência, idade de abandono das fraldas e impacto do(s) sintoma(s) na qualidade de vida). O instrumento era composto por 07 questões, 06 de múltipla escolha abordando aspectos condizentes com cada um dos sintomas enumerados, incluindo confirmação da ocorrência e frequência de acometimento. Para análise da qualidade de vida, reservou-se uma questão, na qual os sujeitos foram ensinados a atribuir uma nota de 0 a 10 de acordo à intensidade com que os sintomas impactavam em seu bem estar. Quanto menor a nota, maior o impacto e mais desconfortável o sujeito frente à situação. Ainda nessa questão, e com o mesmo propósito, utilizou-se de Escala Visual Analógica (EVA), em que expressões faciais indicavam o grau de satisfação (Anexo 1).

As variáveis quantitativas, contínuas ou ordinais, foram descritas por suas medidas de tendência central (médias ou medianas) e pelas respectivas medidas de dispersão (desviopadrão, variação interquartil ou valores mínimo e máximo), enquanto as nominais ou qualitativas, por seus valores absolutos, percentagens ou proporções. O teste $t$ de Student ou o teste de Mann-Whitney foi o instrumento empregado para comparação das diferenças das variáveis contínuas e o Teste de D'Agostino - Pearson, na avaliação do padrão de distribuição das variáveis. Na comparação dos dados categóricos, utilizaram-se os testes de Fisher ou do qui-quadrado e suas variantes. A associação entre os parâmetros estudados foi expressa pela razão de prevalência (Odds Ratio). Intervalos de confiança de $95 \%$ foram empregados como medidas de precisão dos resultados e valores de $\mathrm{p}$ menores que $0,05(\mathrm{p}<0,05)$ considerados significativos. Nas análises, foi utilizado o programa estatístico computacional GraphPad Prism, versão 6.0.3, GraphPad Software, San Diego-CA, USA.

\section{ANÁLISE E DISCUSSÃO DOS RESULTADOS}

Foram avaliados 50 crianças com idade de 10[7-15] anos e discreta predominância do sexo feminino. A maioria dos entrevistados era procedente de Feira de Santana (96\%). Do total, 17 sujeitos apresentavam o genótipo SC (34\%), 28 SS (56\%), 1 (um) S $\alpha$-talassemia (2\%) e quatro não souberam informar (8\%). As características gerais e dados sóciodemográficos estão mais detalhados na tabela 1.

Tabela 1 Características gerais dos entrevistados $(\mathbf{n}=\mathbf{5 0})$

\begin{tabular}{|l|l|l|}
\hline Variáveis & Descrição & n (\%) \\
\hline Sexo & Feminino & $26(52)$ \\
& Masculino & $24(48)$ \\
\hline Idade (anos) & $6-11$ & $29(58)$ \\
& $12-18$ & $15(30)$ \\
& $19-24$ & $6(12)$ \\
\hline Estado civil & Solteiro & $50(100)$ \\
\hline Genótipo & SC & $17(34)$ \\
& SS & $28(56)$ \\
& S-thal & $01(2)$ \\
& Indeterminado & $04(8)$ \\
\hline
\end{tabular}


A enurese noturna foi o sintoma mais prevalente e observada em 21 (42\%) dos casos, acometendo $75 \%$ dos sujeitos aos cinco anos e cerca de 15\% dos adolescentes aos 15 anos de idade (figura 1). Na maioria dos casos episódios de enurese ocorriam de uma a três vezes por semana. $31(62 \%)$ dos sujeitos relataram a ocorrência de pelo menos algum sintoma do trato urinário inferior: 10 (20)\% apresentavam urgência, 5(10\%) enurese diurna, e 12 (24\%) noctúria. A maioria dos sujeitos referiu apresentação de apenas um sintoma, todavia, 10 sujeitos apresentavam 2 ou mais sintomas.

\section{Figura 1 - Prevalência de enurese em função da idade}

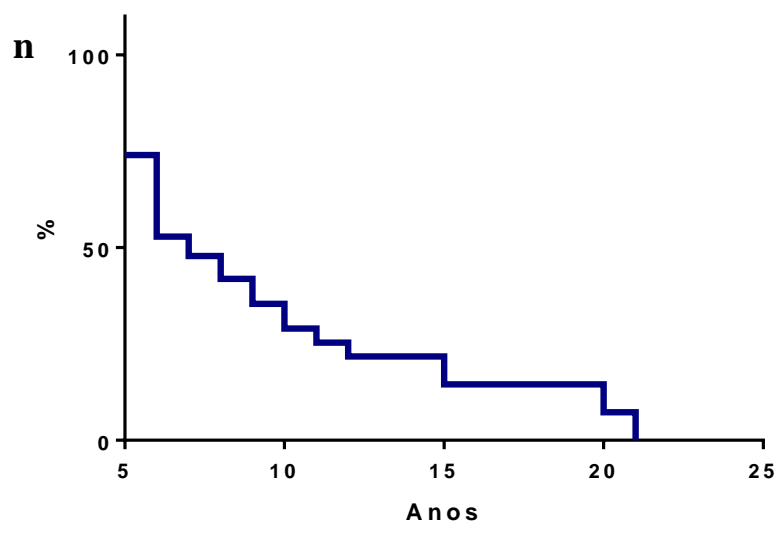

Enurese mostrou-se mais comum em indivíduos masculinos, $(\mathrm{OR}=1,89[0,59-5,38])$, porém sem significância estatística $(\mathrm{p}=0,395)$. Com relação à idade de abandono das fraldas e aquisição do controle esfincteriano: 16 (32\%) abandonaram as fraldas com menos de dois anos, $12(24 \%)$ entre dois e três anos, $10(20 \%)$ entre três e quatro anos, 7 (14\%) entre quatro e cinco, 4 (8\%) após os cinco anos, e duas crianças ainda não estavam desfraldadas. Os STUI impactam negativamente na qualidade de vida dos acometidos. Pacientes assintomáticos apresentavam escores de sintomas significativamente maiores que os sintomáticos respectivamente 9,26 $\pm 0,92$ e 7,22 $\pm 3,44$. p=0,0156. De acordo com a EVA, dentre os sintomáticos, $45 \%$ (14/31) consideraram que STUI impactam gravemente em sua qualidade de vida.

Os sintomas urinários, em especial a enurese, está significativamente aumentada em pacientes com DF, como evidenciado em $42 \%$ dos participantes desse trabalho, entre 6 e 24 anos. Este resultado corrobora outros estudos que reforçam a relação entre DF e STUI (Claudino, 2012; Ekinci, 2016; Silva, 2014; Tewari, 2016; Wolf, 2014). Portocarrero et al (2012) relataram enurese em 32,3\% dos 50 pacientes de cinco a 17 anos com DF. Em outro estudo, que avaliou 45 casos e 45 controles pareados para sexo e idade entre dois e 17 anos, enurese noturna foi de igual forma mais comum entre os casos, porém sem significância estatística (Wolf, 2014). A teoria das causas não mutualmente exclusivas justifica tal resultado no paciente falcêmico (Claudino, 2012).

Apesar de não haver etiologia definida, acredita-se que a predisposição genética possa determinar a presença dos STUI, especialmente em sujeitos cujos pais também possuem a hemoglobinopatia e apresentaram quadro urinário na infância (Ekinci, 2013; Tewari, 2016; Mrad, 2017). Esta associação não pode ser estabelecida devido à ausência de questionamento abrangendo história familiar, fato que pode ser interpretado como limitação do estudo.

Destaca-se a prevalência de enurese noturna em cerca de $15 \%$ dos jovens com 15 anos de idade, bastante elevada se comparada com indivíduos saudáveis. Cita-se que apesar da ocorrência deste sintoma em portadores de DF diminuir com o avançar da idade, a prevalência em adolescentes e adultos ainda supera a encontrada na população em geral (Tewari, 2016; 
MS, 2016). Ainda no estudo conduzido por Portocarrero (2012), em portadores de DF, os sintomas permaneceram em $21 \%$ dos afetados na idade entre 15 e 18 anos. Além da enurese, a prevalência dos demais STUI baseada na sintomatologia foi equivalente ao esperado em portadores de DF, sendo a noctúria o sintoma mais relatado, incontinência diurna e urgência os sintomas mais referidos (Silva, 2014; Mrad, 2017).

A insatisfação em relação à qualidade de vida foi referida por $25,53 \%$ dos sujeitos sintomáticos, atribuída à presença dos STUI. Em estudo conduzido por Lorencini (2015), que contou com a participação de 12 mães de crianças com diagnóstico de DF SS com idade entre 8 e 10 anos, foram referidos como principais consequências psicossociais da DF o comportamento internalizante com maior escore no subitem retraimento (Ekinci, 2013).

\section{CONSIDERAÇÕES FINAIS}

Há forte correlação entre doença falciforme e sintomas do trato urinário inferior e impacto negativo sobre a qualidade de vida dos sujeitos avaliados. O estudo reforça a necessidade de haver interesse constante sobre a ocorrência desses eventos em portadores de tão prevalente hemoglobinopatia.

\section{REFERÊNCIAS}

CANÇADO RD, JESUS, JA. A doença falciforme no Brasil. Rev Bras Hematol Hemoter. 2007;29(3):203-206.

Ministério da Saúde (BR), Secretaria de Ciência, Tecnologia e Insumos Estratégicos. Protocolo Clínico e Diretrizes Terapêuticas Doença Falciforme. Brasília (DF); 2016.

ANELE UA et al. Overactive bladder in adults with sickle cell disease. Neurology and Urodynamics, 2015.

SILVA IV et al. Sickle cell disease in children: chronic complications and search of predictive factors for adverse outcomes. European Journal of Haematology. 2014;94:157-161. ENEH, CI et al. Nocturnal enuresis: prevalence and risk factors among shool-aged children with sickle cell anemia in a South-east Nigerian city. Italian Journal of Pediatrics. 2015;41(66).

EKINCI $\mathrm{O}$ et al. Nocturnal enuresis in sickle cell disease and thalassemia major: associated factors in a clinical sample. Int J Hematol. 2013;98:430-436.

LORENCINI GRF, DE PAULA KMP. Perfil comportamental de crianças com anemia falciforme. Temas em Psicologia. 2015; 23(2):269-280.

CLAUDINO MA; FERTRIN KY. Sickling cells, cyclic nucleotides, and protein kinases: the pathophysiology of urogenital disorders in sickle cell anemia. Anemia. 2012.

TEWARI, $\mathrm{S}$ et al. Nocturnal enuresis and $\mathrm{K}$ transport in red blood cells from patient with sickle cell anemia. Haematologica. 2016;101:e469-e472.

PORTOCARRERO ML et al. Prevalence of enuresis and daytime urinary incontinence in children and adolescents with sickle cell disease. The Journal of Urology. 2012;187:10371040.

WOLF RB et al. Nocturnal enuresis in sickle cell disease. Expert Rev. Hematol. 2014;7(2).

MBONG EM et al. Bedwetting and sleep disorders in sickle cell disease patients in Cameroon. Journal of Neurological Sciences. 2013;333:e679-e727.

FIELD JJ et al. Enuresis is a common and persistent problem among children and young adults with sickle cell anemia. Urology. 2008;72(1):81-84.

MRAD, FCC. Treinamento esfincteriano em crianças com síndrome de Down: um estudo caso controle [tese]. Juiz de Fora: Faculdade de Medicina da Universidade Estadual de Juiz de Fora; 2017. 